\title{
Pulsed Large Volume Injection Gas Chromatography Coupled with Electron- Capture Negative Ionization Quadrupole Mass Spectrometry for Simultaneous Determination of Typical Halogenated Persistent Organic Pollutants
}

\author{
Yuli Zhao, ${ }^{\text {a Limin Yang, }}$, and Qiuquan Wang ${ }^{\mathrm{a}, \mathrm{b}}$ \\ a Department of Chemistry and the MOE Key Laboratory of Modern Analytical Sciences, College of \\ Chemistry and Chemical Engineering, Xiamen University, Xiamen, China \\ b State Key Laboratory of Marine Environmental Science, Xiamen University, Xiamen, China
}

A pulsed large-volume injection gas chromatography coupled with electron-capture negative ionization quadrupole mass spectrometry (pLVI-GC/ECNI-qMS) was developed for the simultaneous determination of typical halogenated persistent organic pollutants (H-POPs). By monitoring the characteristic ions of large mass-to-charge ratio $(\mathrm{m} / \mathrm{z})$ for each of the H-POPs rather than the chlorine and/or bromine ions, this method avoided the possible interferences arising from the H-POPs themselves and from complex matrices encountered frequently in current GC/qMS methods; and allowed, on the other hand, the use of ${ }^{13} \mathrm{C}$-labeled and perdeuterated analogues as internal standards for reliable quantification. pLVI up to $120 \mu \mathrm{L}$ improved the instrumental detection limits down to $\mathrm{pg}-\mathrm{fg} \mathrm{mL} \mathrm{mL}^{-1}$, comparable to or lower than those obtained by the recognized GC/high-resolution MS methods reported so far. The H-POPs including 12 polybrominated diphenyl ethers, 1 polybrominated biphenyl, 10 polychlorinated biphenyls (PCBs), 4 hexachlorocyclohexane isomers, and hexachlorobenzene were involved in this study. The method developed demonstrated good linearity $\left(r^{2}=\right.$ 0.9904-0.9999) within 0.5 to $50,000 \mathrm{pg} \mathrm{mL}^{-1}$ for PCBs and 0.05 to $5000 \mathrm{pg} \mathrm{mL}^{-1}$ for other H-POPs, and was satisfactory in terms of both repeatability $(0.07 \%-2.2 \%)$ and reproducibility $(2.1 \%-8.4 \%)$. It was validated by analyzing a NIST standard reference material SRM-1946 of Lake Superior fish tissue with low 0.01 to $63 \mathrm{pg} \mathrm{g}^{-1}$ method detection limits, and successfully applied to the determination of the H-POPs in five reference materials of different matrices. (J Am Soc Mass Spectrom 2007, 18, 1375-1386) (C 2007 American Society for Mass Spectrometry

$\mathrm{O}$ ver the past few decades, the presence of many man-made halogenated persistent organic pollutants (H-POPs) in the environment have attracted increasing public concern due to the information emerging concerning their persistence, bioaccumulation, and potential risks to human health [1]. Consequently, analytical methodology and strategies for measuring quite a variety of H-POPs classes in environmental and biological samples have been developed rapidly, generally including the procedures from sample collection, pretreatment, and extraction, to cleanup and determination [2,3]. Organochlorinated pesticides (OCPs), such as hexachlorocyclohexane $(\mathrm{HCHs})$ and hexachlorobenzene (HCB), polychlori-

Address reprint requests to Dr. Qiuquan Wang, Department of Chemistry and the MOE Key Laboratory of Modern Analytical Sciences, College of Chemistry and Chemical Engineering, Xiamen University, Xiamen 361005, China. E-mail: qqwang@xmu.edu.cn nated biphenyls (PCBs), polybrominated biphenyls (PBBs), and polybrominated diphenyl ethers (PBDEs) are typical H-POPs. These various classes of contaminants are often present together in the same environmental or biological matrices, coextracted from the same sample, isolated in the same fractions, and even coeluted and/or overlapped from chromatographic systems because of their similarities in molecular structure and physicochemical behavior. From an environmental point of view, simultaneous determination of the H-POPs in environmental samples to allow comparative evaluation and comprehensive documenting is attractive [4].

Major problems in the simultaneous determination of the H-POPs in environmental and biological samples are intra- and interferences caused by the numerous congeners of similar physicochemical properties in each and/or different classes, as well as the interference 
caused by complex matrices. Additionally, the H-POPs, particularly PBDEs, often occur in the environment at extremely low levels [5]. Thus, determination methods with both high selectivity and high sensitivity are demanded. Capillary gas chromatography coupled with an electron capture detector (GC/ECD) and/or mass spectrometry (GC/MS) has been used commonly for the identification and quantification of OCPs, PCBs, PBBs, and PBDEs [6-9]. GC/ECD, a technique offering high sensitivity for the electron-capturing H-POPs, was widely used at an early stage for analyzing OCPs. However, GC/MS is preferred now because absolute chromatographic separation for the individual analyte was difficult even if multidimensional GC was employed [10]. Several GC/MS methods have been established based on high-resolution magnetic-sector MS (HR-MS) [11], tandem MS (MS/MS) using an ion trap detector [12-14], or triple quadrupole analyzer [15] and time-of-flight MS (TOF-MS) [16], as well as lowresolution quadrupole MS (qMS) [17]. Obviously, HR-MS is the most powerful tool offering high selectivity with satisfactory sensitivity by virtue of its high ultimate resolving power and accurate mass measurement; nevertheless, nowadays only a few laboratories can afford this instrument. Alternatively, MS/MS and TOF-MS provide comparable selectivity at a relatively lower cost compared with HR-MS [18]. Due to the advantages of low cost and sufficient sensitivity, qMS is commonly available in current analytical laboratories despite the relatively lower selectivity, which results from its limited resolution ability. Both ionization modes of electron impact (EI) and electron-capture negative ionization (ECNI) are extensively utilized in qMS, but each has its own merits and limitations. Generally, ECNI is significantly more sensitive, while EI is more selective for the low chlorinated PCBs, PBBs, and PBDEs [19-21]. The use of ${ }^{13} \mathrm{C}$-labeled analogues as internal standards under EI ensures reliable quantification compared with ECNI [22]. Recently, strategies have been developed with respect to the determination of PBDEs to overcome the limitations of each technique. Covaci et al. [23] combined narrow-bore $(0.10 \mathrm{~mm}$ i.d.) capillary GC/MS by using EI with large-volume injection (LVI) up to $20 \mu \mathrm{L}$ achieving selective determination at the low $\mathrm{ng} \mathrm{g}^{-1}$ level for five major PBDEs congeners (BDE-28, 47, 99, 100, and 153) in human adipose, yet the sensitivity for the higher brominated $\left(\mathrm{Br}_{7-10}\right)$ PBDEs remained insufficient. Using ECNI, Ackerman et al. [24] novelly monitored specific large mass-to-charge ratio $(m / z)$ fragment ions $\left(\left[\mathrm{M}-\mathrm{H}_{\mathrm{x}}-\mathrm{Br}_{\mathrm{y}}\right]^{-}\right)$instead of the conventional bromine ion $\left({ }^{78.9 / 80.9}[\mathrm{Br}]^{-}\right)$, performing isotope dilution quantification of 39 PBDEs with low ng-pg $\mathrm{mL}^{-1}$ instrumental detection limits (IDLs).

This study aimed to develop and validate a selective and sensitive method based on the simple and popular GC/ECNI-qMS by monitoring characteristic large $\mathrm{m} / \mathrm{z}$ fragment ions and using ${ }^{13} \mathrm{C}$-labeled and/or perdeuterated internal standards as well as employing a pulsed LVI (pLVI) technique for simultaneously determining the H-POPs at trace to ultra-trace levels in complex biological and environmental samples. We targeted 28 typical H-POPs, including five OCPs $(\alpha, \beta, \gamma, \delta-\mathrm{HCH}$, and HCB), 10 PCBs (PCB-28, 52, 101, 105, 118, 138, 153, 163, 180, and 209), one PBB (PBB-153), and 12 PBDEs (BDE-28, 47, 49, 66, 85, 99, 100, 138, 153, 154, 183, and 209) in this study.

\section{Experimental}

\section{Reagents and Chemicals}

The target H-POPs and the ${ }^{13} \mathrm{C}$-labeled and/or perdeuterated analogues used as internal standards are listed in Table $1 .^{\circ}$ All $^{\circ}$ native ${ }^{\circ}$ and $^{\circ}{ }^{13} \mathrm{C}$-labeled ${ }^{\circ}$ standards $^{\circ}$ of PBDEs, PBB, PCBs, and HCB in nonane or iso-octane solutions were purchased from Cambridge Isotope Laboratories (CIL, Andover, MA); neat $\mathrm{HCH}$ standards were purchased from AccuStandard (New Haven, CT), while the $\mathrm{D}_{6}-\alpha-\mathrm{HCH}$ standard in cyclohexane solution was purchased from Dr. Ehrenstorfer GmbH (Augsburg, Germany). All standards were of at least $99 \%$ purity. All the compounds were considered toxic and potentially carcinogenic, and were handled with caution to reduce exposure to the lowest possible level. Dichloromethane and hexane (Tedia, Fairfield, $\mathrm{OH}$ ) were of pesticide grade, and sulfuric acid $\left(\mathrm{H}_{2} \mathrm{SO}_{4}\right.$, Sinic Chemical Reagent Company, SCRC) was of analytical reagent (AR) grade. Before use, anhydrous sodium sulfate $\left(\mathrm{Na}_{2} \mathrm{SO}_{4}, \mathrm{AR}, \mathrm{SCRC}\right)$ and neutral alumina (100200 mesh, SCRC) were extracted with dichloromethane and baked at $350{ }^{\circ} \mathrm{C}$ for $3 \mathrm{~h}$ and $600^{\circ} \mathrm{C}$ for $24 \mathrm{~h}$, respectively.

\section{Instrumentation}

All GC/MS analysis were performed on a GCMSQP2010 (Shimadzu, Kyoto, Japan) equipped with a quadrupole mass analyzer and three ionization sources of EI, positive chemical ionization (PCI) and negative chemical ionization. A DB-17MS capillary column of $30 \mathrm{~m}$ length $\times 0.25 \mathrm{~mm}$ i.d. $\times 0.25 \mu \mathrm{m}$ film thickness (J \& W Scientific, Folsom, CA) was used to analyze all the H-POPs except for BDE-209, which was analyzed separately on a shorter DB-XLB column of $15 \mathrm{~m}$ length $\times 0.25 \mathrm{~mm}$ i.d. $\times 0.25 \mu \mathrm{m}$ film thickness $(\mathrm{J} \& \mathrm{~W}$ Scientific) ${ }^{\circ}$ to $^{\circ}$ reduce ${ }^{\circ}$ possible ${ }^{\circ}$ thermal ${ }^{\circ}$ degradation $^{\circ}[25]$. A deactivated guard column of 5 m length $\times 0.25 \mathrm{~mm}$ i.d. was connected before each column. The GC was equipped with a split/splitless injector and a program temperature vaporizer (PTV), the former for splitless $1-\mu \mathrm{L}$ injection and the latter for pLVI. For the splitless injection, the injector temperature was held at $280^{\circ} \mathrm{C}$, and the splitless time was 4 min for analyzing BDE-209 and 2 min for simultaneously analyzing all the other H-POPs. An AOC-20i autosampler (Shimadzu) equipped with one of three syringes with different capacity, namely 10,50, and $250 \mu \mathrm{L}$, was used to inject the samples. The GC/MS interface was maintained at 


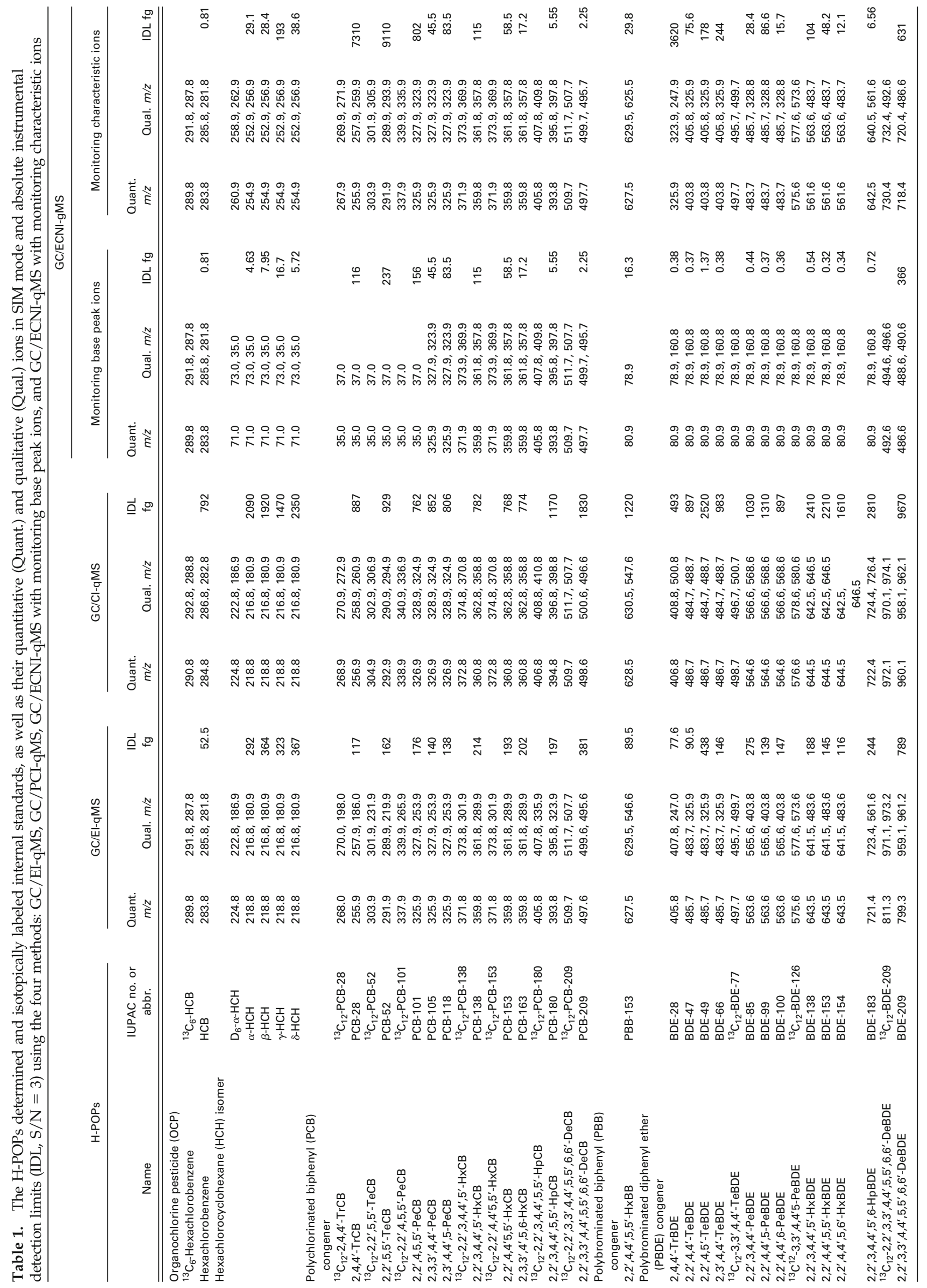


Table 2. The MS optimization parameters and their optimal values using the four methods: GC/EI-qMS, GC/PCI-qMS, GC/ECNIqMS with monitoring base peak ions, and GC/ECNI-qMS with monitoring characteristic ions

\begin{tabular}{|c|c|c|c|c|c|c|}
\hline & \multicolumn{2}{|c|}{ Optimization parameters } & \multicolumn{4}{|c|}{ Optimal values } \\
\hline & Range & Interval & $\begin{array}{l}\text { GC/El- } \\
\text { qMS }\end{array}$ & $\begin{array}{c}\text { GC/PCl- } \\
\text { qMS }\end{array}$ & $\mathrm{ECNI}^{-q M S^{a}}$ & ECNI-qMS \\
\hline Electron energy (eV) & $40-80$ & $5^{c}, 2^{d}$ & $60^{e}, 70^{f}$ & $55^{e}, 65^{f}$ & $70^{e}, 60^{f}$ & $56^{e}, 60^{f}$ \\
\hline Filament emission current $(\mu \mathrm{A})$ & $30-70$ & $5^{c}, 2^{d}$ & $55^{e}, 60^{f}$ & $55^{e}, 60^{f}$ & $65^{e}, 60^{f}$ & $50^{e}, 55^{f}$ \\
\hline Source temperature $\left({ }^{\circ} \mathrm{C}\right)$ & $150-260$ & $10^{\mathrm{c}}, 5^{\mathrm{d}}$ & $200^{e}, 250^{f}$ & $190^{e}, 250^{f}$ & $250^{e}, 250^{f}$ & $195^{\mathrm{e}}, 250^{\mathrm{f}}$ \\
\hline Moderating gas type & $\mathrm{CH}_{4}, i-\mathrm{C}_{4} \mathrm{H}_{10}$ & - & - & $i-\mathrm{C}_{4} \mathrm{H}_{10}{ }^{\mathrm{e}, \mathrm{f}}$ & $i-\mathrm{C}_{4} \mathrm{H}_{10} \mathrm{e}, \mathrm{f}$ & $i-\mathrm{C}_{4} \mathrm{H}_{10} \mathrm{e}, \mathrm{f}$ \\
\hline Moderating gas pressure $\left(10^{-3} \mathrm{~Pa}\right)$ & $2.0-5.0$ & $0.5^{\mathrm{c}}, 0.1^{\mathrm{d}}$ & - & $3.5^{\mathrm{e}}, 2.5^{\mathrm{f}}$ & $2.5^{\mathrm{e}}, 2.0^{\mathrm{f}}$ & $3.6^{\mathrm{e}}, 3.2^{\mathrm{f}}$ \\
\hline
\end{tabular}

a' With monitoring of base peak ions.

bith monitoring of characteristic ions.

'Under $\mathrm{El}$ and $\mathrm{PCl}$.

dUnder ECNI.

eFor simultaneously analyzing all the H-POPs except BDE-209.

${ }^{f}$ For analyzing the BDE-209 separately.

$280^{\circ} \mathrm{C}$. Helium (He, 99.999\%, Linde, Xiamen, China) was used as the GC carrier, and methane $\left(\mathrm{CH}_{4}\right.$, $99.995 \%$, Linde) and isobutane $\left(i-\mathrm{C}_{4} \mathrm{H}_{10}, 99.99 \%\right.$, Linde $)$ were used as the reagent gas and moderating gas in PCI and ECNI modes, respectively.

\section{$p L V I-G C / E C N I-q M S$ with Monitoring of Characteristic Ions}

GC/EI-qMS, GC/PCI-qMS and GC/ECNI-qMS were compared in their selectivity and sensitivity for analyzing the H-POPs. In each ionization mode, full scan mass spectra were recorded for each of the H-POPs, and the MS parameters of electron energy, emission current, ionization temperature, the type and pressure of reagent gas for PCI, and moderating gas for ECNI were

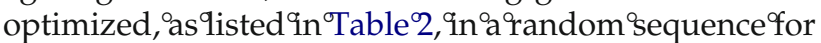
maximum instrumental sensitivity. The optimization experiments were undertaken using $1-\mu \mathrm{L}$ splitless injection of BDE-209 standard solution or mixed standard solution containing all the other H-POPs, and an amount 10 to 40 times higher than the IDL for a given compound was employed. Under optimal conditions, a five-point internal calibration curve was established for each of the H-POPs and the lowest calibration standard was repeatedly injected 11 times to obtain the standard deviation (SD) for determining the IDL for each of the H-POPs.

pLVI was carried out by pulsed injections (12 s per injection) with the autosampler, and the PTV was operated in solvent vent mode. The maximum allowable sample introduction volume (employing hexane as solvent) for pLVI was initially determined by injecting the same amounts of the H-POPs in different volumes, followed by optimizing a number of PTV parameters, such as sample volume per injection, split ratio, initial and final PTV temperature, as well as column inlet pressure during the sample transfer. The optimum PTV parameters were determined based on the requirement that, for each analyte, the mean injection efficiency and repeatability of 11 successive injections must be compa- rable to the 1- $\mu \mathrm{L}$ splitless injection, and that the decomposition of thermally labile components was insignificant. ${ }^{\circ}$ As ${ }^{\circ}$ illustrated ${ }^{\circ}{ }^{\circ}{ }^{\circ}$ Figure ${ }^{\circ} 1,{ }^{\circ} 120^{\circ} \mu \mathrm{L}^{\circ}$ was ${ }^{\circ}$ introduced onto the column by six pulsed injections of $20 \mu \mathrm{L}$ each at an initial temperature of $75^{\circ} \mathrm{C}$ with the split valve open; between adjacent injections, the hexane was evaporated selectively and eliminated via the split vent at the split ratio of 200:1, while the analytes were retained on the packing material ( $8 \mathrm{mg}$ silanized quartz wool) in the liner (straight tube design, $1.2 \mathrm{~mm}$ i.d. $\times 9.5 \mathrm{~cm}$ length, deactivated using dimethyldichlorosilane) by cold trapping. After sample injection and solvent evaporation, the split valve was closed (split ratio $=$ $0: 1$ ) and the PTV rapidly heated up to the final temperature of $280^{\circ} \mathrm{C}$ for transferring the analytes

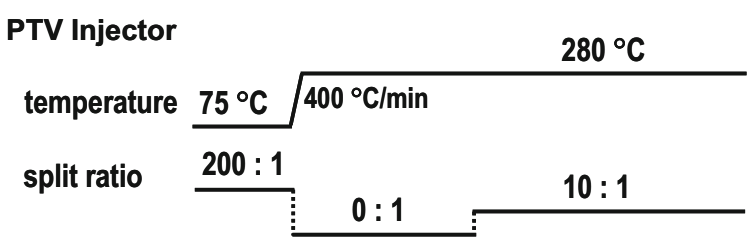

GC Column

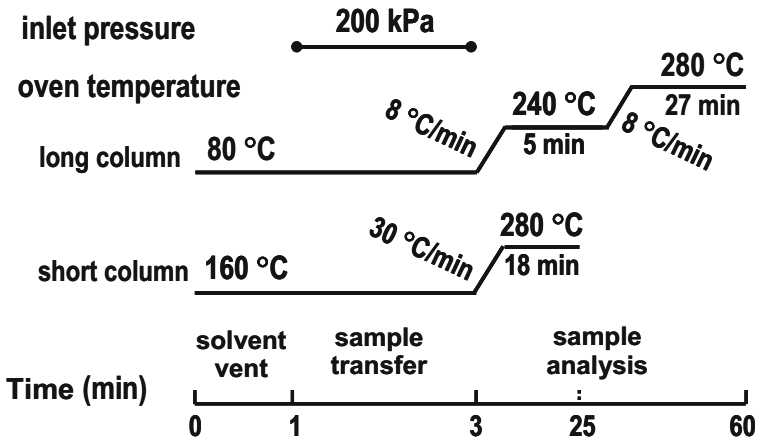

Figure 1. Parameters of the PTV temperature and split ratio as well as the GC column inlet pressure and oven temperature during solvent vent (0-1 $\mathrm{min})$, sample transfer (1-3 min), sample analysis (3-25 $\mathrm{min}$ for BDE-209, and 3-60 $\mathrm{min}$ for the other all H-POPs). 
under a pulsed high-pressure of $200 \mathrm{kPa}$. Once the analyte transfer was finished, the split valve was opened at the split ratio of 10:1 to vent the nonvolatile matrix components. In general, the liner and silanized quartz wool were changed after 500 injections of standards and 100 injections of sample extracts, respectively.

The proposed pLVI-GC/ECNI-qMS was then evaluated. Linearities were determined by creating six-point calibration curves at concentrations of $0.05,0.5,5,50$, 500, and $5000 \mathrm{pg} \mathrm{mL}^{-1}$ for the PBDEs, PBB-153, and OCPs, and $0.5,5,50,500,5000$, and 50,000 $\mathrm{pg} \mathrm{mL}^{-1}$ for the PCBs. IDLs for the H-POPs were determined as the concentration corresponding to three times the SD of 11 measurements of the lowest calibration standard. Repeatability was determined by 11 successive injections of the lowest calibration standards, and reproducibility was determined by seven injections each time, once every two days within two weeks.

\section{Samples and Pretreatment}

A standard reference material (SRM 1946) of Lake Superior fish tissue was purchased from the National Institute of Standards and Technology (NIST, Gaithersburg, MD) for assessing method accuracy. Two grass carps were purchased from a local market to prepare method blank sample. The grass carp samples were ground and homogenized, Soxhlet extracted for $24 \mathrm{~h}$, and then ultrasonically extracted three times using a dichloromethane/hexane (vol/vol $=1 / 1)$ mixture. After confirmation that the final extracts concentrated contained neither the analytes nor chromatographic interferents, the fish tissues obtained were used as method blank samples. Five reference materials of clean soil (EDF-5183), heavily contaminated sediment (EDF5184), clean fish (EDF-2524, Pacific herring), contaminated fish (EDF-2525, Lake Ontario lake trout) and fortified fish (EDF-2526, Sockeye salmon) were purchased from CIL to determine the H-POPs, our laboratory being one of the participating laboratories of the second round of international laboratory study organized by CIL and Cerilliant Corporation from May to August, 2006.

The SRM-1946 fish tissue was analyzed in two batches at an interval of 4 months. Each aliquot of $0.5 \mathrm{~g}$ fish tissue (wet weight) was mixed with $15 \mathrm{~g}$ $\mathrm{Na}_{2} \mathrm{SO}_{4}$ and wrapped into a clean filter paper. After spiking with the internal standards, the samples were Soxhlet extracted with a dichloromethane/hexane $(\mathrm{vol} / \mathrm{vol}=1 / 1)$ mixture for $24 \mathrm{~h}$, throughout which time the container was wrapped with aluminum foil to minimize possible photodegradation of the analytes, particularly BDE-209. The resultant extract was reduced to $15 \mathrm{~mL}$ using a rotary evaporator, and further to $\sim 1 \mathrm{~mL}$ using nitrogen $\left(\mathrm{N}_{2}\right)$ stream, followed by solvent exchange into $5 \mathrm{~mL}$ hexane. The extract then had $5 \mathrm{~mL}$ concentrated $\mathrm{H}_{2} \mathrm{SO}_{4}$ added and was shaken for $5 \mathrm{~min}$ to destroy most of the lipids.
After centrifugation, the upper hexane was decanted and then concentrated to $1 \mathrm{~mL}$ and loaded onto an alumina column $(1.0 \mathrm{~cm}$ i.d. $\times 30 \mathrm{~cm}$ length $)$ packed with $10 \mathrm{~g}$ deactivated neutral alumina for further cleanup. The first eluate of $10 \mathrm{~mL}$ hexane was discarded, while the second fraction of $30 \mathrm{~mL}$ dichloromethane/hexane ( vol/vol = 1/1) was collected, then concentrated under a $\mathrm{N}_{2}$ stream and solvent exchanged into $0.5 \mathrm{~mL}$ hexane. Each batch comprised five replicate samples ensuring analysis precision, a method blank sample, and a spiked method blank sample for checking sample contamination and losses during sample pretreatment. The method determination limits (MDL) for the H-POPs were determined from spiked method blank samples: method blank samples spiked with the corresponding standards at a concentration of about 5 to 10 times the signal to noise ratio $(\mathrm{S} / \mathrm{N})$. Seven replicates of the spiked method blank samples were analyzed using the same procedures described above, and the MDL of each H-POP determined was calculated as the average method blank value plus 10 times the SD. The soil, sediment, and fish reference material samples were each analyzed in one batch comprised five replicates; their pretreatment procedures were the same as the SRM fish tissues described above.

\section{Results and Discussion}

\section{Comparison of EI-qMS, PCI-qMS, and ECNI-qMS for determination of the HOPS}

Mass spectra of the H-POPs strongly depend on the type of ionization source. EI mass spectra are characterized by relatively abundant fragment ions, which offer more information on the molecular structures, while PCI and ECNI mass spectra are simpler. In the EI mass spectra, molecular ions $\left([\mathrm{M}]^{+}\right)$are the base peak ions for all the H-POPs with the exception of HCHs, which fragment ions $\left[\mathrm{M}-\mathrm{Cl}_{2,3,5}\right]^{+}$are base peak ions. In the PCI mass spectra, protonated molecular ions $\left([\mathrm{MH}]^{+}\right)$ are the base peak ions for all the HOCs except for the fragment ions $\left[\mathrm{MH}-\mathrm{Cl}_{2}\right]^{+}$for HCHs. The ECNI mass spectra of HCB and highly chlorinated PCBs (containing more than four chlorine atoms) exhibited dominating molecular ions $\left([\mathrm{M}]^{-}\right.$) as the base peak ions, while those of the HCHs showed strong to moderate fragment $[\mathrm{Cl}]^{-},\left[\mathrm{HCl}_{2}\right]^{-}$, and $[\mathrm{M}-\mathrm{HCl}]^{-}$ions. Nevertheless, the ECNI mass spectra of the lower chlorinated PCB-28 and 52 as well as PBB-153 and PBDEs yield predominant $[\mathrm{Cl}]^{-}$and $[\mathrm{Br}]^{-}$, respectively, but weak $[\mathrm{M}]^{-}$. Exceptionally, the ECNI mass spectra of BDE-209 showed intense to moderate $\left[\mathrm{C}_{6} \mathrm{Br}_{5} \mathrm{O}\right]^{-},\left[\mathrm{C}_{6} \mathrm{Br}_{4} \mathrm{O}\right]^{-}$, and $[\mathrm{Br}]^{-}$agreeing with the $^{\circ}$ findings $^{\circ}$ of ${ }^{\circ}$ previous $^{\circ}$ investigators $^{\circ}[26]^{\circ}$ besides, $^{\circ}$ $\left[\mathrm{M}-\mathrm{Br}_{1-5}\right]^{-}$due to the subsequent losses of bromine atoms from the $[\mathrm{M}]^{-}$were observed in low $1.3 \%$ to $17 \%$ abundance with the expected isotopic pattern. 


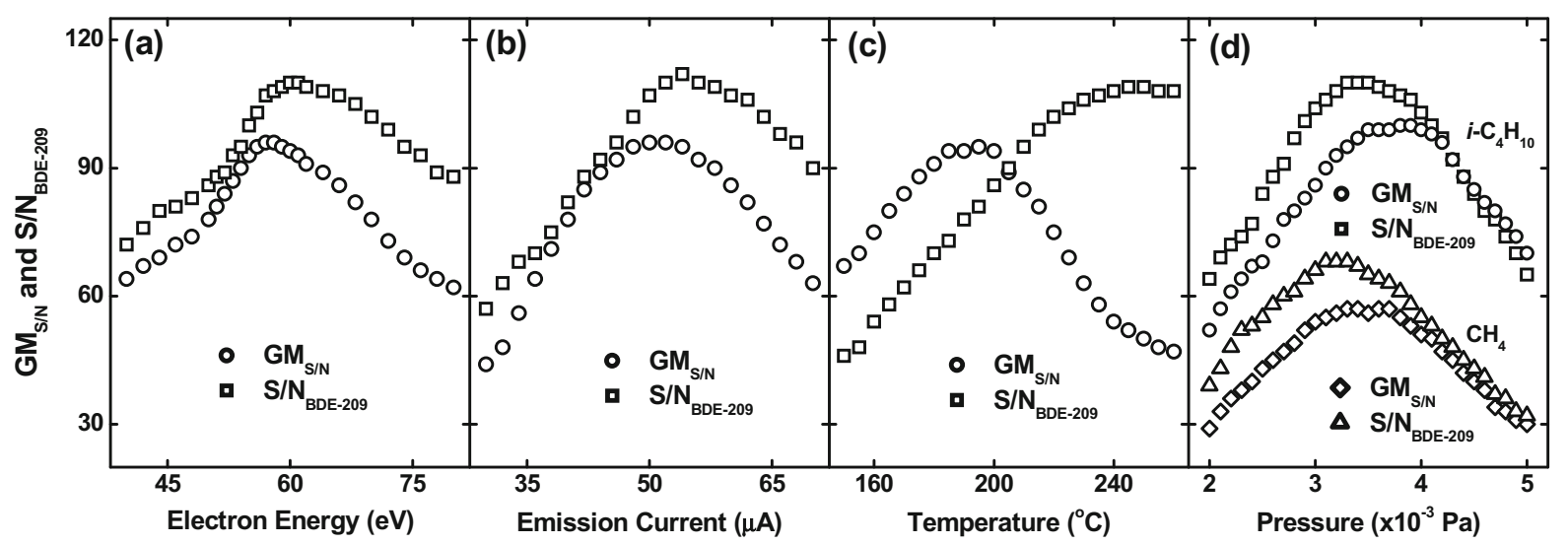

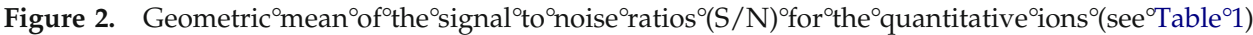
of all the H-POPs except BDE-209 $\left(\mathrm{GM}_{\mathrm{S} / \mathrm{N}}\right)$ and the S/N for the quantitative ion of BDE-209 $\left(\mathrm{S} / \mathrm{N}_{\mathrm{BDE}-209}\right)$ as functions of electron energy $(\mathrm{eV})(\mathbf{a})$, filament emission current $(\mu \mathrm{A})(\mathbf{b})$, ion source temperature $\left({ }^{\circ} \mathrm{C}\right)(\mathbf{c})$, and pressure $\left(\times 10^{-3} \mathrm{~Pa}\right)$ of $i-\mathrm{C}_{4} \mathrm{H}_{10}$ and $\mathrm{CH}_{4}(\mathbf{d})$.

The quantitative and qualitative ions selected for the H-POPs ${ }^{\circ}{ }^{\circ}{ }^{\circ}{ }^{\circ}{ }^{\circ}{ }^{\circ}{ }^{\circ}$ ionization ${ }^{\circ}$ mode $^{\circ}$ are ${ }^{\circ}$ listed $^{\circ}$ in ${ }^{\circ}$ Table $1 .^{\circ} \mathrm{In}^{\circ} \mathrm{EI}^{\circ}$ and ${ }^{\circ} \mathrm{PCI}^{\circ}$ modes, ${ }^{\circ}$ the ${ }^{\circ}$ molecular ${ }^{\circ}$ and ${ }^{\circ}$ large- $m / z$ fragment ions, which were both structurally characteristic and most abundant, were unquestionably selected. In the ECNI mode, two groups of quantitative and qualitative ions were selected because the most abundant ions were not all structurally characteristic for the $\mathrm{H}$-POPs studied. For example, the major $[\mathrm{Br}]^{-}$of almost all the PBDEs, PBB-153, and the major $\left[\mathrm{Cl}^{-}\right.$of the PCB-28, 52 only reflected the element composition of ${ }^{78.9 / 80.9} \mathrm{Br}$ and ${ }^{35.0 / 37.0} \mathrm{Cl}$ but no information on the molecular structure. In this case, either the base peak ion or the characteristic ion may be monitored with different preference to sensitivity or selectivity. Monitoring base peak ions was relatively sensitive but might produce false identification; whereas, monitoring characteristic ions suffered considerable losses in sensitivity although it achieved much better selectivity. As can be seen ${ }^{\circ}$ in $^{\circ}$ Table $^{\circ} 1{ }^{\circ}$, the ${ }^{\circ}$ absolute ${ }^{\circ}$ IDLs $^{\circ}$ of ${ }^{\circ} \gamma$-HCH, ${ }^{\circ}$ PCB-52, BDE-138, and PBB-153 were 16.7, 237, 0.54, and $16.3 \mathrm{fg}$, respectively, when their corresponding base peak ions were monitored, while the IDLs were 193, 9110, 104, and $29.8 \mathrm{fg}$, respectively, when monitoring the corresponding characteristically higher $\mathrm{m} / \mathrm{z}$ ions.

The optimized ionization conditions of EI, PCI, and ECNI for monitoring the base peak ions and/or the characteristicions ${ }^{\circ}\left(\right.$ listed $^{\circ}$ in Table1) ${ }^{\circ}$ when ${ }^{\circ}$ simultaneously analyzing all the H-POPs except BDE-209 and when separatelyanalyzing the BDE-209are given $9 n^{\circ}$ Table 2 . The ECNI mass spectra of the H-POPs were observed to be strongly dependent on the qMS operation conditions of electron energy, filament emission current, ion source temperature, the type of moderating gas, and pressure. Generally, the S/N ratios of the characteristic ions of high $\mathrm{m} / \mathrm{z}$ (listed ${ }^{\circ}$ in $^{\circ}$ Table $\left.^{\circ} 1\right)^{\circ}$ were $^{\circ}$ improved $^{\circ}$ by $^{\circ}$ factors ${ }^{\circ}$ of approximately one order of magnitude after optimization (see ${ }^{\circ}$ Figure 2 ). ${ }^{\circ}{ }^{\circ}{ }^{\circ}{ }^{\circ}$ example, ${ }^{\circ}$ the ${ }^{\circ}$ relative ${ }^{\circ}$ abundance ${ }^{\circ}$ of ${ }^{\circ}[\mathrm{M}$ $-\mathrm{HBr}^{-}(m / z=561.6,563.6)$ for BDE-138 was improved from $0.8 \%$ to $24 \%$. Results suggested that lower electron energy, emission current, ion source temperature, and higher moderating gas pressure facilitated the production of thermal electrons, thus forming more $[\mathrm{M}]^{-}$(for HCB, PCBs, PBB) through a resonance thermal electron capture process or high- $m / z$ fragment ions $\left([\mathrm{M}-\mathrm{HBr}]^{-}\right.$for $\mathrm{PBDE}_{n=3-7}$, $[\mathrm{M}-\mathrm{HCl}]^{-}$for $\mathrm{HCHs}$, and $[\mathrm{M}-3 \mathrm{Br}]^{-}$for BDE-209) through a dissociative resonance electron capture process [27]. Besides, a higher pressure of moderating gas increased the frequency of collision and stabilization of these ions formed. However, extremely low electron energy and emission current decreased the ionization efficiencies, and too much moderating gas hampered the transfer of the ions from the ion source to the quadrupole analyzer; hence, the absolute intensities of the ions were actually reduced. In addition, the results indicated that the optimum pressure using $i-\mathrm{C}_{4} \mathrm{H}_{10}$ as moderating gas was slightly lower than that using $\mathrm{CH}_{4}$ as moderating gas for obtaining a comparable sensitivity.

Comparison of the IDLs between the four GC/ qMS-based ${ }^{\circ}$ methods $^{\circ}\left(\text { Table }^{\circ} 1\right)^{\circ}$ shows $^{\circ}$ that ${ }^{\circ}$ the ${ }^{\circ} \mathrm{GC} /$ ECNI-qMS was the most sensitive for all the H-POPs when the base peak ions were monitored for quantification. Comparatively, the GC/ECNI-qMS with monitoring the characteristic ions were 1 to 200 times less sensitive for the majority of the H-POPs studied, and the sensitivity generally increased along with the increase in the number of $\mathrm{Cl}$ or $\mathrm{Br}$ substitutions in the molecules. For example, IDL of ECNI with monitoring the characteristic $[\mathrm{M}-\mathrm{HBr}]^{-}$for BDE-28 containing $3 \mathrm{Br}$ atoms was 9526 times higher than that with monitoring the $[\mathrm{Br}]^{-}$. This is because the dissociative electron capture dominates the ionization processes of PBDEs, producing primarily $[\mathrm{Br}]^{-}$; additionally, the formation enthalpies of PBDE congeners decrease with $^{\circ}$ the ${ }^{\circ}$ decreasing ${ }^{\circ}$ number ${ }^{\circ}$ of $^{\circ}$ bromines $^{\circ}[28]^{\circ} .^{\circ}$ The IDLs of the GC/EI-qMS were $\sim 1$ to 600 times less sensitive than those of the GC/ECNI-qMS when monitoring the base peak ions, while those of the GC/PCI-qMS were 4 to 15 times less sensitive than the GC/EI-qMS. 


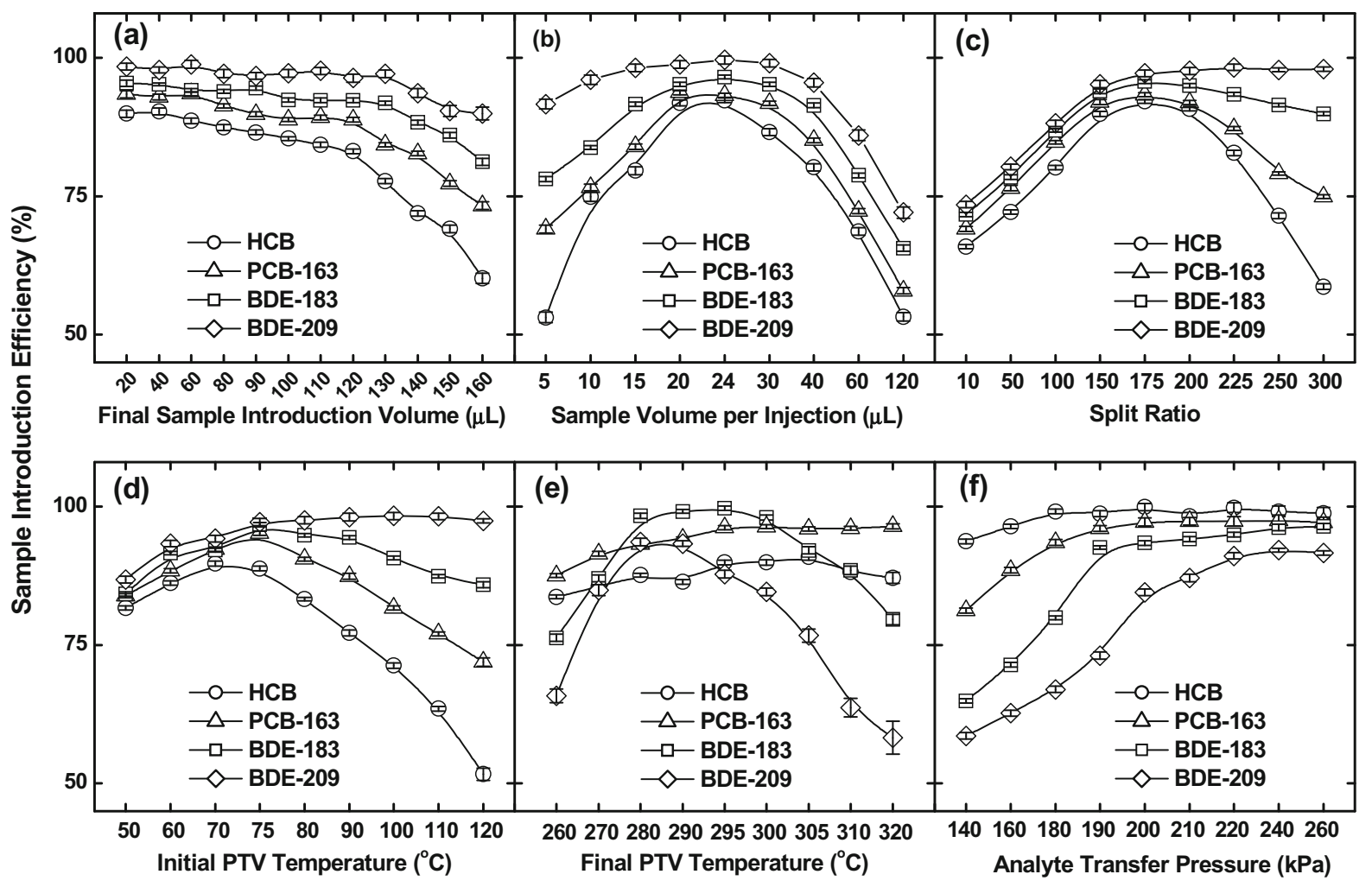

Figure 3. Sample introduction efficiency and repeatability ( $\mathrm{SD}, n=11$, shown as error bars), of the pLVI for HCB, PCB-163, BDE-183, and BDE-209 as a function of final sample introduction volume (a), sample volume per injection (b), split ratio (c), initial PTV temperature (d), final PTV temperature (e), and sample transfer pressure (f).

When analyzing a real sample, selectivity predominance over sensitivity, in terms of many possible chlorinated and/or brominated chromatographic interferences, have been reported, including the naturally-occurring compounds that vary from matrix to matrix and sometimes are more abundant than the analytes ${ }^{\circ}\left[29,{ }^{\circ} 30\right],{ }^{\circ}$ as $^{\circ}$ well $^{\circ}$ as $^{\circ}$ from ${ }^{\circ}$ non-targeted ${ }^{\circ}$ coexisting anthropogenic compounds or between the analytes ${ }^{\circ}[31] .^{\circ} \mathrm{GC} / \mathrm{ECNI}^{-q M S^{\circ}}$ with $^{\circ}$ monitoring $^{\circ}$ of ${ }^{\circ}$ the characteristic ions provided more structural information and thus higher selectivity regardless of the lower sensitivity compared with the GC/ECNI-qMS, with monitoring of the base peak ions. However, the lost sensitivity could be compensated for through the introduction of a larger volume of samples into the analyzing system.

\section{$p L V I-G C / E C N I-q M S$}

The pLVI sample introduction efficiency and repeatability relative ${ }^{\circ}$ to ${ }^{\circ}$ the ${ }^{\circ} 1-\mu L^{\circ}$ splitless ${ }^{\circ}$ injection ${ }^{\circ}$ are $^{\circ}$ shown ${ }^{\circ}$ in Figure $3^{\circ}$ for $^{\circ} \mathrm{HCB},{ }^{\circ} \mathrm{PCB}-163,{ }^{\circ} \mathrm{BDE}-183,{ }^{\circ}$ and ${ }^{\circ} \mathrm{BDE}-209,{ }^{\circ}$ which ${ }^{\circ}$ represent different degrees of volatility and thermal stability. Sample introduction efficiencies for 20 through $120 \mu \mathrm{L}$ sample volumes of all the analytes were higher than $83.1 \%$, while further increase in the injection volume led to unsatisfactory introduction efficiencies for some low boiling $^{\circ}$ point $^{\circ}$ analytes ${ }^{\circ}$ such $^{\circ}$ as $^{\circ} \mathrm{HCB}^{\circ}\left(\right.$ see $^{\circ}$ Figure $^{\circ} 3$ a) ${ }^{\circ}$ When introducing the sample through six pulsed injections of 20 $\mu \mathrm{L}$ each, the sample introduction efficiencies obtained were between $92.3 \%$ to $99.6 \%$ for all the H-POPs studied (Figure3b). Lowerand 9arger'samplevolume perinjection produced an evaporation loss of relatively volatile compounds and the liner flooding losses of the samples via the split vent, respectively. Different analytes had different optimal split ratio and initial temperature depending on their ${ }^{\circ}$ boiling ${ }^{\circ}$ points ${ }^{\circ}$ (Figure $3 \mathrm{c}^{\circ}$ and $\left.{ }^{\circ} \mathrm{d}\right){ }^{\circ}$, when ${ }^{\circ}$ the ${ }^{\circ}$ split ${ }^{\circ}$ ratio and initial temperature were increased from 10:1 to 300:1 and from 50 to $120^{\circ} \mathrm{C}$, respectively. Lower split ratio and initial temperature were insufficient for timely venting of all the solvent during the injection intervals and thus resulted in liner flooding losses of all the analytes, while higher split ratio and initial temperature led to losses of lower boiling point compounds. Similar phenomena have been ${ }^{\circ}$ reported ${ }^{\circ}$ previously ${ }^{\circ}[32]{ }^{\circ}$ As ${ }^{\circ}$ shown ${ }^{\circ}$ in Figure ${ }^{\circ} 3 \mathrm{e}^{\circ}$ and $^{\circ} \mathrm{f}^{\circ}, \mathrm{a}^{\circ}$ final ${ }^{\circ}$ temperature ${ }^{\circ}$ of $280^{\circ} \mathrm{C}^{\circ}$ combined with a pulsed high-pressure of $200 \mathrm{kPa}$ was efficient in transferring the higher boiling point compounds; however, much higher temperature and pressure led to decomposition of BDE-209 and slight leakage of carrier gas.

\section{Performance of the pLVI-GC/ECNI-qMS}

Although many chromatographically co-eluting interferences have been previously reported when using a column of 5\% diphenyl-95\% dimethylsiloxane (typi- 


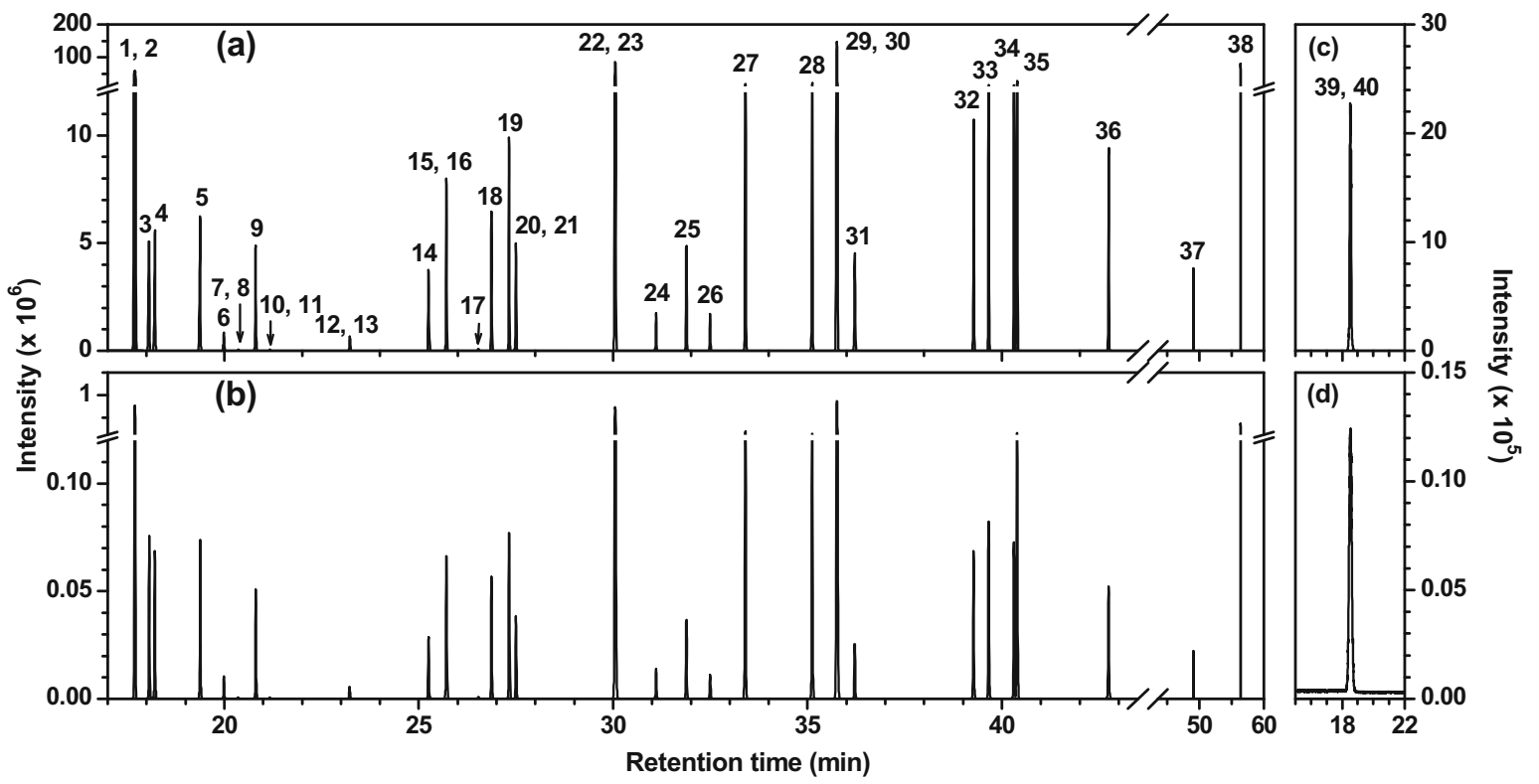

Figure 4. Chromatograms obtained from the mixture of the H-POPs standards in hexane with SIM mode (the concentrations of $\mathrm{HCB}$ and ${ }^{13} \mathrm{C}_{6}-\mathrm{HCB}$ were $10 \mathrm{pg} \mathrm{mL}{ }^{-1}$, and those of the other H-POPs and the corresponding $\mathrm{D}_{6}$ - and ${ }^{13} \mathrm{C}_{12}$-internal standards were $100 \mathrm{pg} \mathrm{mL} \mathrm{m}^{-1}$ ) using $120-\mu \mathrm{L}$ pLVI (a) and $1-\mu \mathrm{L}$ splitless injection (b); those from BDE-209 and ${ }^{13} \mathrm{C}_{12}$-BDE-209 mixture (500 pg mL ${ }^{-1}$, respectively) using $120-\mu \mathrm{L}$ pLVI (c) and 1- $\mu \mathrm{L}$ splitless injection (d). The peak numbers of H-POPs are the same ${ }^{\circ}{ }^{\circ}$ those $^{\circ}$ in $^{\circ} \mathrm{Table}^{\circ} 3$.

cally including the interferences between BDE-28 and PCB-118, BDE-47 and PCB-180, BDE-154 and PBB-153, PCB-163 ${ }^{\circ}$ and $^{\circ}$ PCB-138 $\left.{ }^{\circ}[9]\right),{ }^{\circ}$ baseline $^{\circ}$ separation $^{\circ}$ was achieved by using a DB-17MS column within $60 \mathrm{~min}$ divided into 20 retention time windows for all the H-POPs, except for the partial overlap between BDE$154^{\circ}$ and $^{\circ}{ }^{\circ}$ BB- $153^{\circ}$ (Figure $\left.{ }^{\circ} 4\right)$. Interference between ${ }^{\circ}$ PBB153 and BDE-154 was solved by monitoring their different characteristic ions at $\mathrm{m} / z=627.5$ for PBB-153 and $m / z=561.6$ for BDE-154. By using pLVI, the sample amount finally introduced onto the column was increased by more than two orders of magnitude compared with the normal $1-\mu \mathrm{L}$ splitless injection.

Performance parameters of the pLVI-GC/ECNI-qMS developed $^{\circ}$ are $^{\circ}$ summarized $^{\circ}$ in $^{\circ}$ Table $^{\circ} 3 .^{\circ}$ The $^{\circ}$ pLVI-GC/ ECNI-qMS provided lower IDLs for the H-POPs, ranging from $10 \mathrm{fg} \mathrm{mL}^{-1}$ of HCB to $87.5 \mathrm{pg} \mathrm{mL}^{-1}$ of PCB-52. The IDLs were significantly improved by factors of 81.0 to 208 compared with those using the 1- $\mu \mathrm{L}$ splitless injection, while improved by factors of 1.63 to 121 (except for the 0.011 to 0.87 of BDE-28, 47, 49, 66, 99, 138, and 153) compared with those using the GC/ECNI-qMS monitoring base peak ions with $1-\mu \mathrm{L}$ splitless injection. The method also exhibited good linearity with correlation coefficients of 0.9904 to 0.9999 , satisfied repeatability of $0.1 \%$ to $2.2 \%$, and reproducibility of $2.1 \%$ to $8.4 \%$ for the H-POPs. On the other hand, the method allowed the use of ${ }^{13} \mathrm{C}$-labeled and/or perdeuterated analogues as internal standards for reliable quantification of all the H-POPs studied, which is not possible for the HCHs, PCB-28, PCB-52, PBDEs, and PBB-153, when monitoring their corresponding base peak ions.

\section{Method Validation and Comparison with Other Methods}

The H-POP concentrations in the SRM 1946 were determined by using the pLVI-GC/ECNI-qMS, and the results are $^{\circ}$ presented ${ }^{\circ}{ }^{\circ}{ }^{\circ} \mathrm{Table}^{\circ} 4 .{ }^{\circ} \mathrm{The}^{\circ}$ determined ${ }^{\circ}$ concentrations are well in accordance with the certified and/or reported values 933,34$],{ }^{\circ}$ demonstrating ${ }^{\circ}$ good ${ }^{\circ}$ accuracy ${ }^{\circ}$ of the ${ }^{\circ} \mathrm{pLVI}-$ GC/ECNI-qMS developed. Moreover, concentrations of the $\beta-, \delta-\mathrm{HCH}$, and BDE-49, 138, 209 in the SRM 1946 were determined as $0.98 \pm 0.07,0.13 \pm 0.01,1.81 \pm 0.08,0.35 \pm$ 0.06 , and $0.93 \pm 0.12 \mathrm{ng} \mathrm{g}^{-1}$ wet weight for the first time. Most of the H-POPs were not detected in the method blank samples except for $\gamma-\mathrm{HCH}\left(8.6 \mathrm{pg} \mathrm{g}^{-1}\right)$, PCB-138 (2.6 pg g $\left.{ }^{-1}\right)$, PCB-153 $\left(2.2 \mathrm{pg} \mathrm{g}^{-1}\right)$, BDE-99 $\left(2.3 \mathrm{pg} \mathrm{g}^{-1}\right)$, BDE-100 $\left(1.2 \mathrm{pg} \mathrm{g}^{-1}\right)$, BDE-183 $\left(0.4 \mathrm{pg} \mathrm{g}^{-1}\right)$, and BDE-209 $\left(1.21 \mathrm{ng} \mathrm{g}^{-1}\right)$. All the method blanks, with the exception of BDE-209, were below $1 \%$ of the concentrations determined in the SRM sample, and the blank-corrected result was reported for BDE-209. Recoveries of the internal standards from the SRM samples were $74.2 \%$ to $97.9 \%$, and the precision of the 10 replicate measurements was less than $18.4 \%$. MDLs of the pLVI-GC/ECNI-qMS for the H-POPs were 0.01 to $63 \mathrm{pg} \mathrm{g}^{-1}$, most of which were lower than those listed by US EPA in Method 1668 and 1614 using ${ }^{\circ}$ the ${ }^{\circ} \mathrm{GC} / \mathrm{HR}-\mathrm{MS}^{\circ}[35,36]$.

\section{Application to Soil, Sediment, and Fish Reference Materials}

The developed pLVI-GC/ECNI-qMS was applied to determine the H-POPs contents in the five CIL reference 
Table 3. Performance of the pLVI-GC/ECNI-qMS with monitoring characteristic ions

\begin{tabular}{|c|c|c|c|c|c|c|c|c|c|}
\hline \multirow{2}{*}{$\begin{array}{l}\text { Retention } \\
\text { time window } \\
\text { (min) }\end{array}$} & \multirow{2}{*}{$\begin{array}{c}\text { Retention } \\
\text { time } \\
\text { (min) }\end{array}$} & \multicolumn{2}{|r|}{ Compound } & \multirow{2}{*}{$\begin{array}{l}\text { Instrumental } \\
\text { detection limit } \\
(\mathrm{IDL}, \mathrm{pg} \mathrm{mL} \text { ) }\end{array}$} & \multicolumn{2}{|c|}{$\begin{array}{l}\text { IDL's } \\
\text { improvement } \\
\text { factor }\end{array}$} & \multirow[b]{2}{*}{$\begin{array}{c}\text { Linearity } \\
\left(r^{2}\right)\end{array}$} & \multirow{2}{*}{$\begin{array}{c}\text { Repeatability } \\
\text { (RSD \%, } \\
\text { n = 11) }\end{array}$} & \multirow[b]{2}{*}{$\begin{array}{l}\text { Reproducibility } \\
(\mathrm{RSD} \%, \mathrm{n}=7)\end{array}$} \\
\hline & & $\begin{array}{c}\text { Peak } \\
\text { no. }\end{array}$ & Name & & a & $b$ & & & \\
\hline \multirow[t]{2}{*}{$16.0-17.9$} & 17.698 & 1 & ${ }^{13} \mathrm{C}_{6}-\mathrm{HCB}$ & & & & & & \\
\hline & 17.700 & 2 & $\mathrm{HCB}$ & 0.01 & 81 & 81 & 0.9999 & 1.5 & 6.2 \\
\hline \multirow[t]{2}{*}{$17.9-18.8$} & 18.070 & 3 & $\mathrm{D}_{6}-\alpha-\mathrm{HCH}$ & & & & & & \\
\hline & 18.215 & 4 & $\alpha-\mathrm{HCH}$ & 0.29 & 100 & 16 & 0.9997 & 0.4 & 3.1 \\
\hline \multirow[t]{2}{*}{$18.8-20.2$} & 19.380 & 5 & $\beta-\mathrm{HCH}$ & 0.27 & 105 & 29.4 & 0.9996 & 1.0 & 4.8 \\
\hline & 19.990 & 6 & $\gamma-\mathrm{HCH}$ & 1.91 & 101 & 8.74 & 0.9999 & 1.3 & 5.6 \\
\hline \multirow[t]{2}{*}{$20.2-20.6$} & 20.358 & 7 & 13С12-РСВ-28 & & & & & & \\
\hline & 20.360 & 8 & PCB-28 & 71.3 & 103 & 1.63 & 0.9991 & 1.1 & 5.2 \\
\hline $20.6-21.0$ & 20.810 & 9 & $\delta-\mathrm{HCH}$ & 0.38 & 102 & 15.1 & 0.9999 & 0.7 & 3.9 \\
\hline \multirow[t]{2}{*}{$21.0-22.2$} & 21.178 & 10 & ${ }^{13} \mathrm{C}_{12}$-PCB-52 & & & & & & \\
\hline & 21.180 & 11 & PCB-52 & 87.5 & 104 & 2.71 & 0.9979 & 0.9 & 4.7 \\
\hline \multirow[t]{2}{*}{$22.2-24.1$} & 23.223 & 12 & ${ }^{13} \mathrm{C}_{12}$-PCB-101 & & & & & & \\
\hline & 23.225 & 13 & PCB-101 & 7.61 & 105 & 20.5 & 0.9981 & 1.4 & 5.9 \\
\hline $24.1-25.5$ & 25.255 & 14 & PCB-118 & 0.79 & 106 & 106 & 0.9996 & 2.2 & 8.4 \\
\hline \multirow[t]{2}{*}{$25.5-26.1$} & 25.713 & 15 & ${ }^{13} \mathrm{C}_{12}$-PCB-153 & & & & & & \\
\hline & 25.715 & 16 & PCB-153 & 0.54 & 108 & 108 & 0.9997 & 1.0 & 4.9 \\
\hline \multirow{2}{*}{$26.1-27.1$} & 26.540 & 17 & BDE-28 & 33.4 & 108 & 0.011 & 0.9995 & 1.8 & 7.2 \\
\hline & 26.875 & 18 & PCB-105 & 0.43 & 106 & 106 & 0.9998 & 1.2 & 5.3 \\
\hline \multirow[t]{3}{*}{$27.1-28.7$} & 27.325 & 19 & PCB-163 & 0.16 & 108 & 108 & 0.9997 & 1.7 & 6.9 \\
\hline & 27.503 & 20 & ${ }^{13} \mathrm{C}_{12}-$ - & & & & & & \\
\hline & 27.505 & 21 & PCB-138 & 1.07 & 107 & 107 & 0.9997 & 1.3 & 5.7 \\
\hline \multirow[t]{2}{*}{$28.7-30.6$} & 30.053 & 22 & ${ }^{13} \mathrm{C}_{12}-\mathrm{PCB}-180$ & & & & & & \\
\hline & 30.055 & 23 & PCB-180 & 0.05 & 111 & 111 & 0.9999 & 0.8 & 4.4 \\
\hline \multirow[t]{3}{*}{$30.6-33.0$} & 31.105 & 24 & BDE-49 & 1.58 & 113 & 0.87 & 0.9993 & 1.1 & 5.2 \\
\hline & 31.880 & 25 & BDE-47 & 0.67 & 113 & 0.55 & 0.9999 & 1.8 & 7.1 \\
\hline & 32.490 & 26 & BDE-66 & 2.14 & 114 & 0.18 & 0.9985 & 2.1 & 8.2 \\
\hline $33.0-34.3$ & 33.405 & 27 & ${ }^{13} \mathrm{C}_{12}$-BDE-77 & & & & & & \\
\hline $34.3-35.4$ & 35.120 & 28 & BDE-100 & 0.14 & 112 & 2.57 & 0.9999 & 1.9 & 7.4 \\
\hline \multirow[t]{2}{*}{$35.4-38.0$} & 35.758 & 29 & ${ }^{13} \mathrm{C}_{12}-$ PCB-209 & & & & & & \\
\hline & 35.760 & 30 & PCB-209 & 0.02 & 113 & 113 & 0.9999 & 0.2 & 2.3 \\
\hline \multirow[t]{3}{*}{$38.0-40.0$} & 36.215 & 31 & BDE-99 & 0.76 & 114 & 0.49 & 0.9987 & 1.2 & 5.4 \\
\hline & 39.270 & 32 & ${ }^{13} \mathrm{C}_{12}$-BDE-126 & & & & & & \\
\hline & 39.660 & 33 & BDE-85 & 0.25 & 114 & 1.76 & 0.9991 & 0.6 & 3.7 \\
\hline \multirow[t]{2}{*}{$40.0-41.6$} & 40.280 & 34 & PBB-153 & 0.27 & 110 & 60.4 & 0.9994 & 0.4 & 3.2 \\
\hline & 40.400 & 35 & BDE-154 & 0.11 & 110 & 3.09 & 0.9997 & 0.1 & 2.1 \\
\hline \multirow[t]{2}{*}{$41.6-52.0$} & 42.745 & 36 & BDE-153 & 0.38 & 127 & 0.84 & 0.9990 & 0.2 & 2.4 \\
\hline & 49.115 & 37 & BDE-138 & 0.92 & 113 & 0.59 & 0.9993 & 0.07 & 2.1 \\
\hline $\begin{array}{l}52.0-60.0 \\
\text { Short column }\end{array}$ & 56.395 & 38 & BDE-183 & 0.05 & 131 & 14.4 & 0.9927 & 0.5 & 3.3 \\
\hline $16-25.0$ & 21.740 & 39 & ${ }^{13} \mathrm{C}_{12}$-BDE-209 & & & & & & \\
\hline & 21.742 & 40 & BDE-209 & 3.03 & 208 & 121 & 0.9904 & 1.9 & 7.5 \\
\hline
\end{tabular}

${ }^{a}$ Calculated as the ratio of the IDL of the GC/ECNI-qMS with monitoring characteristic ions using 1- $\mu$ L splitless injection to that using $120-\mu \mathrm{L} p \mathrm{VI}$. ${ }^{b}$ Calculated as the ratio of the IDL of the GC/ECNI-qMS with monitoring base peak ions using $1-\mu \mathrm{L}$ splitless injection to that of the GC/ECNI-qMS with monitoring characteristic ions using $120-\mu \mathrm{L}$ pLVI.

${ }^{\mathrm{c}}$ For analyzing BDE-209.

materials for an interlaboratory study from May to Au-

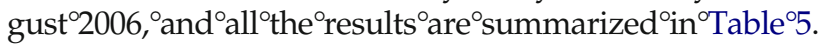
RSDs between the five replicates for all the H-POPs determined were respectively $6.2 \%$ to $23 \%, 3.2 \%$ to $15 \%$, $4.8 \%$ to $18 \%, 5.5 \%$ to $23 \%, 0.41 \%$ to $16 \%$ for the clean soil, heavily contaminated sediment, clean fish, contaminated fish, and fortified fish; and recoveries of the internal standards were $64 \%$ to $95 \%, 74 \%$ to $105 \%, 61 \%$ to $95 \%$, $71 \%$ to $93 \%$, and $65 \%$ to $101 \%$, respectively. Difference in the recoveries between different reference samples might be attributed to the difference in the matrices, especially for the different fish species due to different lipid contents.

\section{Conclusions}

A novel pLVI-GC/ECNI-qMS with monitoring of characteristic ions was developed, validated, and applied for the simultaneous determination of typical H-POPs in environmental and biological reference materials. It could be a superior alternative, demonstrating compa- 


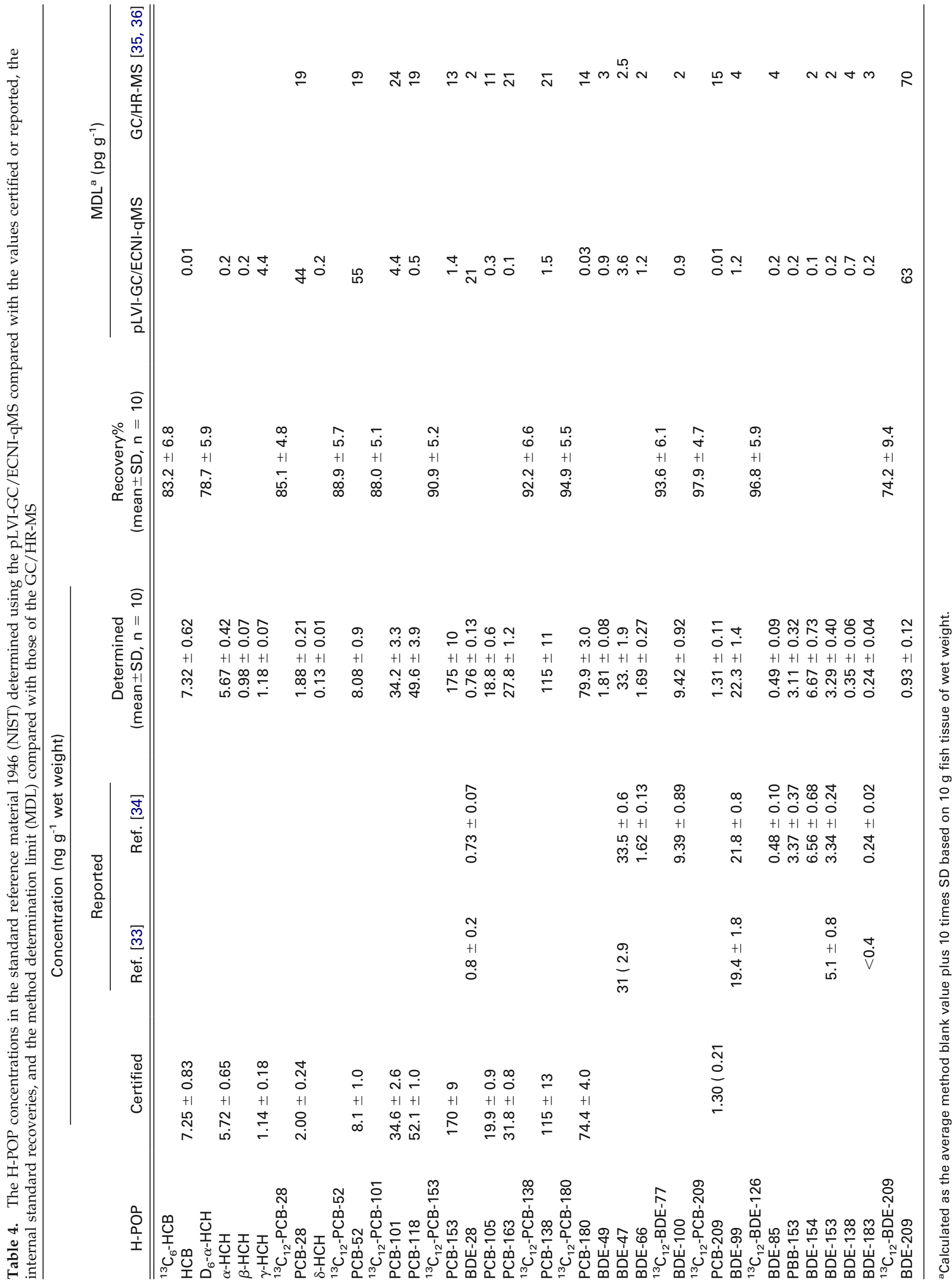


Table 5. The H-POPs concentrations measured in the five reference materials (mean $\pm \mathrm{SD}, n=5$ )

\begin{tabular}{|c|c|c|c|c|c|}
\hline Compound & EDF-5183 & EDF-5184 & EDF-2524 & EDF-2525 & EDF-2526 \\
\hline & \multicolumn{5}{|c|}{ Concentration $\left(\mathrm{ng} \mathrm{g}^{-1}\right)$} \\
\hline HCB & $2.46 \pm 0.21$ & $8.77 \pm 0.53$ & $0.41 \pm 0.03$ & $13.6 \pm 1.1$ & $3.50 \pm 0.11$ \\
\hline$\alpha-\mathrm{HCH}$ & $5.18 \pm 0.32$ & $5.57 \pm 0.67$ & $0.30 \pm 0.03$ & $2.14 \pm 0.30$ & $2.99 \pm 0.17$ \\
\hline$\beta-\mathrm{HCH}$ & $0.63 \pm 0.08$ & $4.50 \pm 0.68$ & $0.24 \pm 0.02$ & $0.86 \pm 0.09$ & $1.43 \pm 0.07$ \\
\hline$\gamma-\mathrm{HCH}$ & $1.35 \pm 0.10$ & $39.4 \pm 4.3$ & $0.21 \pm 0.01$ & $0.49 \pm 0.06$ & $26.8 \pm 0.11$ \\
\hline$\delta-\mathrm{HCH}$ & $7.58 \pm 0.93$ & $6.03 \pm 0.59$ & $0.17 \pm 0.01$ & $2.59 \pm 0.20$ & $6.76 \pm 0.34$ \\
\hline PCB-28 & $0.52 \pm 0.08$ & $61.2 \pm 3.1$ & $0.40 \pm 0.07$ & $8.28 \pm 0.89$ & $0.44 \pm 0.04$ \\
\hline PCB-52 & $1.50 \pm 0.11$ & $1470 \pm 160$ & $0.75 \pm 0.09$ & $26.7 \pm 2.6$ & $0.46 \pm 0.06$ \\
\hline PCB-101 & $4.89 \pm 1.11$ & $3110 \pm 100$ & $1.11 \pm 0.11$ & $82.2 \pm 7.4$ & $0.71 \pm 0.10$ \\
\hline PCB-105 & $0.65 \pm 0.06$ & $917 \pm 101$ & $0.29 \pm 0.03$ & $37.6 \pm 4.3$ & $0.12 \pm 0.01$ \\
\hline PCB-118 & $6.39 \pm 0.41$ & $2560 \pm 260$ & $0.70 \pm 0.05$ & $129 \pm 10$ & $0.32 \pm 0.04$ \\
\hline PCB-138 & $2.03 \pm 0.30$ & $3460 \pm 290$ & $1.03 \pm 0.15$ & $196 \pm 15$ & $0.43 \pm 0.07$ \\
\hline PCB-153 & $2.26 \pm 0.34$ & $4010 \pm 500$ & $1.49 \pm 0.11$ & $275 \pm 17$ & $0.61 \pm 0.09$ \\
\hline PCB-163 & $0.36 \pm 0.08$ & $844 \pm 91$ & $0.82 \pm 0.10$ & $40.3 \pm 4.6$ & $0.35 \pm 0.04$ \\
\hline PCB-180 & $0.99 \pm 0.08$ & $2650 \pm 300$ & $0.47 \pm 0.05$ & $109 \pm 7$ & $0.14 \pm 0.02$ \\
\hline PCB-209 & $0.25 \pm 0.03$ & \multicolumn{4}{|c|}{ Concentration $\left(\mathrm{pg} \mathrm{g}^{-1}\right)$} \\
\hline PBB-153 & $37.8 \pm 2.9$ & $59.7 \pm 5.4$ & $66.5 \pm 5.5$ & $3100 \pm 270$ & $11.8 \pm 1.0$ \\
\hline BDE-28 & $29.7 \pm 3.4$ & $26.6 \pm 3.0$ & $23.7 \pm 2.6$ & $274 \pm 31$ & $16.3 \pm 1.5$ \\
\hline BDE-47 & $267 \pm 31$ & $99.8 \pm 7.1$ & $516 \pm 62$ & $8030 \pm 450$ & $30.5 \pm 2.7$ \\
\hline BDE-49 & $14.4 \pm 1.3$ & $139 \pm 15.1$ & $121 \pm 9.8$ & $413 \pm 29$ & $12.1 \pm 1.0$ \\
\hline BDE-66 & $20.6 \pm 2.5$ & $62.1 \pm 6.9$ & $25.9 \pm 2.4$ & $568 \pm 76$ & $2.6 \pm 0.3$ \\
\hline BDE-85 & $22.3 \pm 2.8$ & $24.5 \pm 1.9$ & $23.7 \pm 2.6$ & $375 \pm 57$ & $5.1 \pm 0.5$ \\
\hline BDE-99 & $32.5 \pm 4.2$ & $50.5 \pm 3.4$ & $44.9 \pm 4.8$ & $1690 \pm 150$ & $9.8 \pm 1.0$ \\
\hline BDE-100 & $12.7 \pm 1.6$ & $24.4 \pm 1.3$ & $35.9 \pm 4.0$ & $1440 \pm 120$ & $9.6 \pm 0.9$ \\
\hline BDE-138 & $12.6 \pm 1.3$ & $12.8 \pm 1.4$ & $22.1 \pm 3.9$ & $378 \pm 86$ & $7.1 \pm 0.7$ \\
\hline BDE-153 & $34.1 \pm 2.5$ & $10.9 \pm 1.2$ & $15.4 \pm 1.3$ & $2010 \pm 200$ & $3.3 \pm 0.3$ \\
\hline BDE-154 & $27.2 \pm 1.9$ & $26.0 \pm 1.8$ & $12.2 \pm 1.6$ & $2110 \pm 200$ & nd \\
\hline BDE-183 & $223 \pm 32$ & $81.0 \pm 8.9$ & $40.9 \pm 2.4$ & $156 \pm 25$ & $19.1 \pm 1.3$ \\
\hline BDE-209 & $691 \pm 63$ & $7620 \pm 860$ & & & \\
\hline
\end{tabular}

nd, not detected.

rable selectivity and lower detection limit, to GC/HRMS. Using ${ }^{13} \mathrm{C}$-labeled and/or perdeuterated internal standard calibration for reliable quantification was an additional feature of this method. Furthermore, the method could be extended to the determination of other trace H-POPs in various environmental and biological matrices at $\mathrm{pg} \mathrm{g}^{-1}$ level or below, in combination with suitable matrix-selective extraction and analyte-specific cleanup procedures soon.

\section{Acknowledgments}

This study was supported financially by the National Natural Science Foundation of China (20475046, 20535020), the National Basic Research Program of China (2003CD415001), and the National 863 Project of China (2006AA06Z404). The loan of the Shimadzu GC-MS QP2010 is gratefully acknowledged. Professor John Hodgkiss is thanked for his assistance with English.

\section{References}

1. Eljarrat, E.; Barcelo, D. Priority Lists for Persistent Organic Pollutants and Emerging Contaminants Based on Their Relative Toxic Potency in Environmental Samples. Trends Anal. Chem. 2003, 22, 655-665.

2. Koester, C. J.; Simonich, S. L.; Esser, B. K. Environmental Analysis. Anal. Chem. 2003, 75, 2813-2829.

3. Liu, H. X.; Zhang, Q. H.; Cai, Z. W.; Li, A.; Wang, Y. W.; Jiang, G. B. Separation of Polybrominated Diphenyl Ethers, Polychlorinated Biphenyls, Polychlorinated Dibenzo-p-Dioxins, and Dibenzo-Furans in Environmental Samples Using Silica Gel and Florisil Fractionation Chromatography. Anal. Chim. Acta. 2006, 557; 314-320.
4. Pirard, C.; De Pauw, E.; Focant, J.-F. New Strategy for Comprehensive Analysis of Polybrominated Diphenyl Ethers, Polychlorinated Dibenzop-Dioxins, Polychlorinated Dibenzofurans, and Polychlorinated Biphenyls by Gas Chromatography Coupled with Mass Spectrometry. J. Chromatogr. A 2003, 998, 169-181.

5. Hites, R. A. Polybrominated Diphenyl Ethers in the Environment and in People: A Meta-Analysis of Concentrations. Environ. Sci. Technol. 2004, 38, 945-956.

6. Santos, F. J.; Galceran, M. T. The Application of Gas Chromatography to Environmental Analysis. Trends Anal. Chem. 2002, 21, 672-685.

7. de Boer, J. Capillary Gas Chromatography for the Determination of Halogenated Microcontaminants. J. Chromatogr. A 1999, 843, 179-198.

8. Chu, S. G.; Hong, C.-S.; Rattner, B. A.; McGowan, P. C. Methodological Refinements in the Determination of 146 Polychlorinated Biphenyls, Including Nonortho- and Monoortho-Substituted PCBs, and 26 organochlorine pesticides as Demonstrated in Heron Eggs. Anal. Chem. 2003, $75,1058-1066$.

9. Alaee, M.; Backus, S.; Cannon, C. Potential Interference of PBDEs in the Determination of PCBs and Other Organochlorine Contaminants Using Electron Capture Detection. J. Sep. Sci. 2001, 24, 465-469.

10. Korytar, P.; Haglund, P.; de Boer, J.; Brinkman, U. A. T. Comprehensive Two-Dimensional Gas Chromatography for the Analysis of Organohalogenated Microcontaminants. Trends Anal. Chem. 2006, 25, 373-396.

11. Liu, H. X.; Zhang, Q. H.; Song, M. Y.; Jiang, G. B.; Cai, Z. W. Method of Development for the Analysis of Polybrominated Diphenyl Ethers, Polychlorinated Biphenyls, Polychlorinated Dibenzo-p-Dioxins, and Dibenzo-Furans in Single Extract of Sediment Samples. Talanta 2006, 70, 20-25.

12. Zeng, E. Y.; Chou, C. C.; Yu, C. Potential Application of Gas Chromatography/Tandem Mass Spectrometry in the Measurement of Coeluting Isomers. Anal. Chem. 2002, 74, 4513-4518.

13. Clarkson, P. J.; Larrazabal-Moya, D.; Staton, I.; McLeod, C. W.; Ward D. B.; Sharifi, V. N.; Swithenbank, J. The Use of Tree Bark as a Passive Sampler for Polychlorinated Dibenzo-p-Dioxins and Furans. Int. J. Environ. Anal. Chem. 2002, 82, 843-850.

14. Cai, Z. W.; Jiang, G. B. Determination of Polybrominated Diphenyl Ethers in Soil from e-Waste Recycling Site. Talanta 2006, 70, 88-90.

15. Hernandez, F.; Portoles, T.; Pitarch, E.; Lopez, F. J.; Beltran, J.; Vazquez, C. Potential of Gas Chromatography Coupled to Triple Quadrupole Mass Spectrometry for Quantification and Confirmation of Organohalo- 
gen Xenoestrogen Compounds in Human Breast Tissues. Anal. Chem. 2005, 77, 7662-7672.

16. Focant, J.-F.; Sjodin, A.; Turner, W. E.; Patterson, D. G., Jr. Measurement of Selected Polybrominated Diphenyl Ethers, Polybrominated and Polychlorinated Biphenyls, and Organochlorine Pesticides in Human Serum and Milk Using Comprehensive Two-Dimensional Gas Chromatography Isotope Dilution Time-of-Flight Mass Spectrometry. Anal. Chem. 2004, 76, 6313-6320.

17. Korytar, P.; Parera, J.; Leonards, P. E. G.; de Boer, J.; Brinkman, U. A. T. Quadrupole Mass Spectrometer Operating in the Electron-Capture Negative Ion Mode as Detector for Comprehensive Two-Dimensional Gas Chromatography. J. Chromatogr. A 2005, 1067, 255-264.

18. Santos, F. J.; Galceran, M. T. Modern Developments in Gas Chromatography-Mass Spectrometry-Based Environmental Analysis. J. Chromatogr. A 2003, 1000, 125-151.

19. Rothweiler, B.; Berset, J.-D. High Sensitivity of Ortho-Substituted Polychlorobiphenyls in Negative Ion Mass Spectrometry (NCI-MS): A Comparison with EI-MS and ECD for the Determination of Regulatory PCBs in Soils. Chemosphere 1999, 38, 1517-1532.

20. Hyotylainen, T.; Hartonen, K. Determination of Brominated Flame Retardants in Environmental Samples. Trends Anal. Chem. 2002, 21, 13-29.

21. Stapleton, H. M. Instrumental Methods and Challenges in Quantifying Polybrominated Diphenyl Ethers in Environmental Extracts: A review. Anal. Bioanal. Chem. 2006, 386, 807-817.

22. Eljarrat. E.; Lacorte, S.; Barcelo, D. Optimization of Congener-Specific Analysis of 40 Polybrominated Diphenyl Ethers by gas Chromatography/Mass Spectrometry. J. Mass Spectrom. 2002, 37, 76-84.

23. Covaci, A.; de Boer, J.; Ryan, J. J.; Voorspoels, S.; Schepens, P. Determination of Polybrominated Diphenyl Ethers and Polychlorinated Biphenyls in Human Adipose Tissue by Large-Volume Injection Narrow-Bore Capillary Gas Chromatography/Electron Impact Low-Resolution Mass Spectrometry. Anal. Chem. 2002, 74, 790-798.

24. Ackerman, L. K.; Wilson, G. R.; Simonich, S. L. Quantitative Analysis of 39 Polybrominated Diphenyl Ethers by Isotope Dilution GC/LowResolution MS. Anal. Chem. 2005, 77, 1979-1987.

25. Bjorklund, J.; Tollback, P.; Hiarne, C.; Dyremark, E.; Ostman, C. Influence of the Injection Technique and the Column System on Gas
Chromatographic Determination of Polybrominated Diphenyl Ethers. J. Chromatogr. A 2004, 1041, 201-210.

26. Bjorklund, J.; Tollback, P.; Ostman, C. Mass Spectrometric Characteristics of Decabromodiphenyl Ether and the Application of Isotopic Dilution in the Electron Capture Negative Ionization Mode for the Analysis of Polybrominated Diphenyl ethers. J. Mass Spectrom. 2003, 38, 394-400.

27. Ong, V. S.; Hites, R. A. Electron Capture Mass Spectrometry of Organic Environmental Contaminants. Mass Spectrom. Rev. 1994, 13, 259-283.

28. Zeng, X.; Freeman, P. K.; Vasil'ev, Y. V.; Voinov, V. G.; Simonich, S. L.; Barofsky, D. F. Theoretical Calculation of Thermodynamic Properties of Polybrominated Diphenyl Ethers. J. Chem. Eng. Data 2005, 50, 1548 1556.

29. Vetter, W. A GC/ECNI-MS Method for the Identification of Lipophilic Anthropogenic and Natural Brominated Compounds in Marine Samples. Anal. Chem. 2001, 73, 4951-4957.

30. Teuten, E. L.; Xu, L.; Reddy, C. M. Two Abundant Bioaccumulated Halogenated Compounds are Natural Products. Science 2005, 307, 917-920.

31. Eljarrat, E.; de la Cal, A.; Barcelo, D. Potential Chlorinated and Brominated Interferences on the Polybrominated Diphenyl Ether Determinations by Gas Chromatography-Mass Spectrometry. J. Chromatogr. A 2003, 1008, 181-192.

32. Tollback, P.; Bjorklund, J.; Ostman, C. Large-Volume ProgrammedTemperature Vaporizer Injection for Fast Gas Chromatography with Electron Capture and Mass Spectrometric Detection of Polybrominated Diphenyl Ethers. J. Chromatogr. A 2003, 991, 241-253.

33. Stapleton, H.; Schantz, M.; Wise, S. Measurement of Polybrominated Diphenyl Ethers in Environmental Matrix Standard Reference Materials. Organohalogen Comp. 2004, 66, 3745-3748

34. Zhu, L. Y.; Hites, R. A. Determination of Polybrominated Diphenyl Ethers in Eenvironmental Standard Reference Materials. Anal. Chem. 2003, 75, 6696-6700.

35. US EPA Method 1668 Revision A, Chlorinated Biphenyl Congeners in Water, Soil, Sediment, and Tissue by HRGC/HRMS

36. US EPA Draft Method 1614, Brominated Diphenyl Ethers in Water, Soil, Sediment, and Tissue by HRGC/HRMS. 